\title{
The effect of guar gum and level and source of dietary fat on glucose tolerance in growing pigs*
}

\author{
BY IAN E. SAMBROOK AND ANNA L. RAINBIRD \\ Nutrition Department, National Institute for Research in Dairying, \\ Shinfield, Reading, RG2 $9 A T$
}

(Received 22 November 1984 - Accepted 25 January 1985)

1. Six growing pigs $(30-75 \mathrm{~kg}$ ) were fed on semi-purified diets containing either $30 \mathrm{~g}$ maize oil $/ \mathrm{kg} \mathrm{diet} \mathrm{(LFM),}$ $30 \mathrm{~g}$ soya-bean oil-tallow mixture $(1: 1, \mathrm{w} / \mathrm{w}) / \mathrm{kg} \operatorname{diet}($ LFST) or $160 \mathrm{~g}$ soya-bean oil-tallow mixture $(1: 1, \mathrm{w} / \mathrm{w}) / \mathrm{kg}$ diet (HFST) without and with the addition of guar gum $(40 \mathrm{~g} / \mathrm{kg} \mathrm{diet})$.

2. Plasma glucose and insulin concentrations following twice daily feeding at 09.00 and $21.00 \mathrm{~h}$ were measured, during $24 \mathrm{~h}$ periods, in blood sampled from a permanent indwelling vena cava catheter.

3. The source and level of dietary fat had no significant effect on pre-prandial plasma glucose or insulin concentrations except for insulin with diet LFST in the morning $(P<0.05)$. Addition of guar gum to the diets had no significant effect on pre-prandial plasma glucose and insulin levels.

4. The peak post-prandial plasma glucose and insulin levels were not significantly affected by dietary fat. The addition of guar gum, however, significantly reduced $(P<0.05)$ the peak post-prandial plasma glucose concentration with diets LFM and LFST and also the peak plasma insulin concentration for all diets except for diet HFST in the morning.

5. The time taken to reach the peak post-prandial plasma glucose and insulin concentrations was not significantly affected by dietary fat but it was increased by the addition of guar gum, although the differences were not always significant.

The beneficial effects of such types of dietary fibre as guar gum on glucose tolerance (Jenkins et al. 1976) and in the management of diabetes (Jenkins et al. 1980) are now well established. However, the mode of action of guar gum in reducing post-prandial hyperglycaemia remains unclear. Among the gastrointestinal mechanisms which may be affected by guar gum are gastric emptying rate, transit time through the small intestine, rate of enzymesubstrate mixing, rate of absorption of nutrients from the small intestine and gastrointestinal hormone profile. Detailed studies of the mechanisms involved are limited by ethical considerations in man, so growing pigs have been used as a model for man, making use of techniques already well established at the National Institute for Research in Dairying.

An initial experiment (Leeds et al. 1980) showed that when guar gum was added to the diet, the post-prandial plasma glucose and insulin peaks in the pig were delayed, smaller, and of extended duration, as had previously been found in man (Jenkins et al. 1976). The fat content of the diet used in this initial experiment was typical of a practical pig diet (i.e. $<50 \mathrm{~g}$ fat $/ \mathrm{kg}$ diet and mostly unsaturated). Human diets, however, generally contain much higher levels of fat than this (both saturated and unsaturated) contributing up to $40 \%$ of gross energy intake. Therefore, for the study reported here, a high-fat semi-purified diet ( $160 \mathrm{~g}$ fat $/ \mathrm{kg}$ diet) containing both saturated and unsaturated fat and more typical of the composition of human diets was formulated and its palatability for growing pigs was tested. The effect on glucose tolerance of changes in fat level and source of dietary fat was then studied, both without and with the addition of guar gum to the diet.

* A preliminary report of this work was presented at the International Symposium on Dietary Fibre in Human and Animal Nutrition held in May 1982 at Palmerston North, New Zealand. 
Table 1. Composition of experimental diets $(\mathrm{g} / \mathrm{kg}$ diet $)$

\begin{tabular}{|c|c|c|c|}
\hline \multirow[b]{2}{*}{ Ingredients } & \multicolumn{3}{|c|}{ Diet } \\
\hline & LFM & LFST & HFST \\
\hline Maize starch & $680 \cdot 9$ & $680 \cdot 9$ & $550 \cdot 9$ \\
\hline Maize oil* & $30 \cdot 0$ & - & - \\
\hline Soya-bean oil $\dagger$ & - & $15 \cdot 0$ & $80 \cdot 0$ \\
\hline Megalac 95 (tallow) & - & $15 \cdot 0$ & $80 \cdot 0$ \\
\hline Casein & $180 \cdot 0$ & $180 \cdot 0$ & $180 \cdot 0$ \\
\hline Solkafloc & $60 \cdot 0$ & $60 \cdot 0$ & $60 \cdot 0$ \\
\hline Trace mineral mix $\$$ & $10 \cdot 0$ & $10 \cdot 0$ & $10 \cdot 0$ \\
\hline Vitamin mix $\|$ & $2 \cdot 0$ & $2 \cdot 0$ & $2 \cdot 0$ \\
\hline Dicalcium phosphate & $31 \cdot 0$ & $31 \cdot 0$ & $31 \cdot 0$ \\
\hline Choline hydrochloridef & $1 \cdot 1$ & $1 \cdot 1$ & $1 \cdot 1$ \\
\hline Sodium chloride & $5 \cdot 0$ & $5 \cdot 0$ & $5 \cdot 0$ \\
\hline Vitamin $B_{12}(\mu \mathrm{g}) \pi$ & 30 & 30 & 30 \\
\hline
\end{tabular}

* Medyna maize oil; London Oil Medina Ltd, London.

$\dagger$ Sainsbury's soya oil; J. Sainsbury Ltd, London.

$\ddagger$ Volac, Royston, Herts.

$\S$ Supplied (/kg diet): $4.47 \mathrm{~g} \mathrm{~K}_{2} \mathrm{CO}_{3}, 1.73 \mathrm{~g} \mathrm{MgCO}_{3} \cdot \mathrm{H}_{2} \mathrm{O}, 0 \cdot 33 \mathrm{~g} \mathrm{FeSO} \cdot 7 \mathrm{H}_{2} \mathrm{O}, 80 \mathrm{mg} \mathrm{MnSO} 4.4 \mathrm{H}_{2} \mathrm{O}, 0 \cdot 10 \mathrm{~g}$ $\mathrm{ZnCO}_{3}, 8 \mathrm{~g} \mathrm{NaF}, 17 \cdot 5 \mathrm{mg} \mathrm{CuSO} \mathrm{g}_{4} .5 \mathrm{H}_{2} \mathrm{O}, 6 \mathrm{mg} \mathrm{CoCl}$.

If Supplied (/kg diet): $12.5 \mathrm{mg}$ retinol, $0.6 \mathrm{mg}$ cholecalciferol, $3.25 \mathrm{mg}$ riboflavin, $2.0 \mathrm{mg}$ thiamin, $15.75 \mathrm{mg}$ nicotinic acid, $16.0 \mathrm{mg}$ pantothenic acid, $3.25 \mathrm{mg}$ pyridoxine, $4.0 \mathrm{mg}$ DL- $\alpha$-tocopheryl acetate, $5.0 \mathrm{mg}$ biotin, $1.0 \mathrm{mg}$ pteroylmonoglutamic acid, $195 \mathrm{mg}$ myo-inositol, $30.0 \mathrm{mg}$ ascorbic acid, $2.0 \mathrm{mg}$ menadione, $20.0 \mathrm{mg}$ p-aminobenzoic acid. All vitamins supplied by Roche Products Ltd, Dunstable, Beds., except myo-inositol from SAS Chemicals Ltd, London and $p$-aminobenzoic acid from BDH Chemicals, Poole, Dorset.

I BDH Chemicals, Poole, Dorset.

\section{METHODS}

\section{Animals and surgery}

Six male Large White $\times$ Landrace pigs of $30 \mathrm{~kg}$ initial live weight were used; they were housed in metabolism crates throughout the trial. The pigs were surgically prepared with an indwelling catheter made from a $900 \mathrm{~mm}$ length of sterile, transparent vinyl tubing $(800 / 000 / 125 / 900$; Portex Ltd, Hythe, Kent) inserted into the anterior vena cava. The animals were first anaesthetized with Brietal sodium (Elanco Products Ltd, Basingstoke, Hants) injected into an ear vein, and approximately $100 \mathrm{~mm}$ of tubing was inserted into the anterior vena cava through a $100 \mathrm{~mm}$ long stainless steel needle (13 gauge). The remaining tubing was led subcutaneously to the back of the neck where it was exteriorized and held in place with an elastic bandage. The catheter was filled with approximately $2 \mathrm{ml}$ sterile saline ( $9 \mathrm{~g}$ sodium chloride/1) containing 30 units Heparin Injection $\mathrm{BP} / \mathrm{ml}$ (Boots Co. Ltd, Nottingham) and the end was plugged with a metal pin. The heparinized saline was replaced daily and also after sampling.

\section{Diets}

Three semi-purified diets with different fat contents were used. These were two low-fat diets containing either $30 \mathrm{~g}$ maize oil/kg diet (LFM) or $30 \mathrm{~g}$ soya-bean oil-tallow mixture $(1: 1$, $\mathrm{w} / \mathrm{w}) / \mathrm{kg}$ diet (LFST) and a high-fat diet containing $160 \mathrm{~g}$ soya-bean oil-tallow mixture $(1: 1, \mathrm{w} / \mathrm{w}) / \mathrm{kg}$ diet (HFST). The composition of the diets is shown in Table 1.

The diets were fed without and with guar gum (Meyprogat 150, Meyhall Chemical (UK) Ltd, Wirral, Merseyside) added at a level of $40 \mathrm{~g}$ guar gum $/ \mathrm{kg}$ air-dry diet. Each pig was fed each of the six diets in a randomized order. The animals were weighed weekly and fed 
according to a scale based on their live weight. The scale used was $75 \%$ of the Shinfield feeding scale of Barber et al. (1972) (3\% body-weight/d), and food was offered twice daily in equal meals at 09.00 and 21.00 hours. Air-dry diet and water were fed in the ratio, $1: 2.5$ $(w / v)$. Guar gum was carefully mixed into the water using a sieve and an electric mixer; the diet was then mixed in slowly to provide a virtually lump-free meal, which was left to stand for $15 \mathrm{~min}$ before feeding.

\section{Blood sampling}

After $3 \mathrm{~d}$ adaptation to the diet, blood samples were taken over a $24 \mathrm{~h}$ period at the following times: two pre-feed samples at 08.45 and 08.55 hours, then $09.15,09.30,09.45$, $10.00,10.15,10.30,10.45,11.00,12.00,13.00,15.00,17.00,19.00,20.55$ (p.m. pre-feed sample), 21.15, 21.30, 21.45, 22.00, 22.15, 22.30, 22.45, 23.00, 24.00, 01.00, 03.00, 05.00, 07.00 and 09.00 hours. Samples from 08.45 to 20.55 were regarded as 'day' samples and the rest as 'night' samples.

Before each sample was taken, all the heparinized saline and about $1 \mathrm{ml}$ blood were withdrawn from the catheter and discarded. Immediately afterwards, a $7 \mathrm{ml} \mathrm{sample} \mathrm{of} \mathrm{blood}$ was withdrawn and transferred to a centrifuge tube. The catheter was then refilled with $2 \mathrm{ml}$ heparinized saline and the end plugged.

The blood samples were immediately centrifuged for $15 \mathrm{~min}$ at $1500 \mathrm{~g}$ in an MSE Minor bench-top centrifuge (MSE Instruments, Manor Royal, Crawley, West Sussex). A $2 \mathrm{ml}$ sample of plasma was stored at $-20^{\circ}$ for insulin assay. A further $2 \mathrm{ml}$ of plasma was treated with $4 \mathrm{ml}$ trichloracetic acid $(100 \mathrm{~g} / 1 ; \mathrm{BDH}$ Chemicals Ltd, Poole, Dorset). After shaking, the mixture was left to stand overnight at $4^{\circ}$ to allow complete precipitation of plasma proteins. It was then centrifuged as described previously and the supernatant fraction was stored at $-20^{\circ}$ to await glucose analysis.

\section{Insulin assay}

The method used for the radioimmunoassay of insulin was a modification of that reported by Tindal et al. (1978). A diluted plasma sample $(200 \mu \mathrm{l})$, or standard bovine insulin (Wellcome Reagents Ltd, Beckenham, Kent) in an equivalent volume and concentration of insulin-free plasma, was preincubated for $24 \mathrm{~h}$ at $4^{\circ}$ with guinea-pig antiserum to porcine insulin (100 $\mu$ l, final dilution 1:300000; Wellcome Reagents Ltd). There was 100\% cross reactivity between bovine and porcine insulins under the test conditions in this assay. ${ }^{125}$ I-labelled insulin (approximately $10 \mathrm{pg}$ in a volume of $200 \mu \mathrm{l}$; Amersham International plc, Amersham, Bucks) was then added and the incubation continued for a further $24 \mathrm{~h}$ at $4^{\circ}$. Finally, donkey antiserum to guinea-pig gamma-globulin $(200 \mu \mathrm{l}$, final dilution 1:160; Guildhay antisera, Dept of Biochemistry, University of Surrey, Guildford, Surrey) and normal guinea-pig serum $(100 \mu \mathrm{l}$, final dilution 1:1600) were added. The mixture was again incubated for $24 \mathrm{~h}$ at $4^{\circ}$ and then centrifuged at $1500 \mathrm{~g}$ for $25 \mathrm{~min}$ in a Mistral $6 \mathrm{~L}$ centrifuge (MSE Instruments). After separation the residue in the tubes was counted for radioactivity for 2 min on an Inter Technique CG 4000 gamma sample counter (Kontron, St Albans, Herts).

\section{Glucose analysis}

Plasma glucose was measured in the deproteinized samples using an automated glucose oxidase (EC 1.1.3.4)-peroxidase (EC 1.11.1.7) method (Boehringer Mannheim, Mannheim, West Germany).

\section{Statistical analysis}

A randomized block design was used. Comparisons between treatments of mean values for pre-prandial concentrations, peak post-prandial concentrations and the time taken to reach the peaks, for both plasma glucose and insulin, were made using analysis of variance and 
Table 2. Pre-prandial plasma glucose and insulin concentrations after pigs received diets with different types and levels of fat, without and with guar gum

(Mean values and standard error of differences between means)

\begin{tabular}{|c|c|c|c|c|}
\hline \multirow[b]{2}{*}{ Diet* } & \multicolumn{2}{|c|}{ Day $\dagger$} & \multicolumn{2}{|c|}{ Night $\dagger$} \\
\hline & $\begin{array}{l}\text { Without } \\
\text { guar }\end{array}$ & $\begin{array}{l}\text { With } \\
\text { guar }\end{array}$ & $\begin{array}{l}\text { Without } \\
\text { guar }\end{array}$ & $\begin{array}{l}\text { With } \\
\text { guar }\end{array}$ \\
\hline & & \multicolumn{3}{|c|}{ Plasma glucose $(\mathrm{mmol} / \mathrm{l})$} \\
\hline $\begin{array}{l}\text { LFM } \\
\text { LFST } \\
\text { HFST }\end{array}$ & $\begin{array}{l}5.81 \\
6.03 \\
5.95\end{array}$ & $\begin{array}{l}5.97 \\
5.93 \\
5.67\end{array}$ & $\begin{array}{l}5 \cdot 58 \\
6 \cdot 05 \\
6 \cdot 20\end{array}$ & $\begin{array}{l}6.04 \\
6.30 \\
5.83\end{array}$ \\
\hline SED $\ddagger$ & \multicolumn{2}{|c|}{$0 \cdot 310$} & \multicolumn{2}{|c|}{0.392} \\
\hline \multicolumn{5}{|c|}{ Plasma insulin ( $\mathrm{m} \mathrm{U} / \mathrm{l}$ ) } \\
\hline $\begin{array}{l}\text { LFM } \\
\text { LFST } \\
\text { HFST }\end{array}$ & $\begin{array}{l}20 \cdot 5^{\mathrm{a}} \\
47 \cdot 1^{\mathrm{b}} \\
18 \cdot 8^{\mathrm{a}}\end{array}$ & $\begin{array}{l}33 \cdot 4 \\
31 \cdot 8 \\
30 \cdot 9\end{array}$ & $\begin{array}{l}40 \cdot 0 \\
65 \cdot 7 \\
28 \cdot 5\end{array}$ & $\begin{array}{l}55 \cdot 8 \\
49 \cdot 4 \\
53 \cdot 0\end{array}$ \\
\hline SED $\ddagger$ & \multicolumn{2}{|c|}{11.52} & \multicolumn{2}{|c|}{18.81} \\
\hline
\end{tabular}

There was no significant effect of guar gum with any diet on either plasma glucose or insulin concentrations. $a, b$ Values within a vertical column with different superscript letters were significantly different $(P<0.05)$.

* For details of diets, see Table 1.

† There were no significant differences between day and night values (glucose, SED 0.304; insulin, SED 17.45).

$\ddagger$ SED for comparison of diets using the harmonic mean number of pigs/diet $(5 \cdot 29)$ based on interactions between pigs and diets $(21 \mathrm{df})$.

a $t$ test. Similarly, day and night values for these measurements were also compared, using a $t$ test. The analysis included computation of missing values for one pig in each of four treatments. Therefore the SED was adjusted using the harmonic mean number of pigs per treatment $(5 \cdot 29)$.

The possibility that factors affecting fasting plasma glucose and insulin levels might have influenced peak post-prandial levels was investigated using covariance analysis of their concentrations, but no significant relations were found.

\section{RESULTS}

There were no practical difficulties in mixing the high-fat diet. All the diets were highly palatable.

The mean pre-prandial plasma glucose and insulin concentrations are shown in Table 2. The type or amount of dietary fat did not affect the pre-prandial plasma glucose values. The pre-prandial plasma insulin values, however, were higher for diet LFST than for the other two diets, although the difference was significant $(P<0.05)$ only before the day feed. Addition of guar gum to the diet had no significant effect on either day or night pre-prandial plasma glucose and insulin levels, although a greatly reduced difference between diets in pre-prandial insulin levels was seen.

The mean peak post-prandial plasma glucose and insulin concentrations are shown in Table 3. The type or amount of dietary fat did not affect the values obtained. However, guar gum reduced the peak plasma concentrations of glucose and insulin, although this was not significant with diet HFST except for insulin after the night feed. There were no significant differences between responses to day and night feeds, except for insulin following diet HFST without guar gum. 
Table 3. Peak post-prandial plasma glucose and insulin concentrations after pigs received diets with different levels of fat, without and with guar gum

(Mean values and standard error of differences between means)

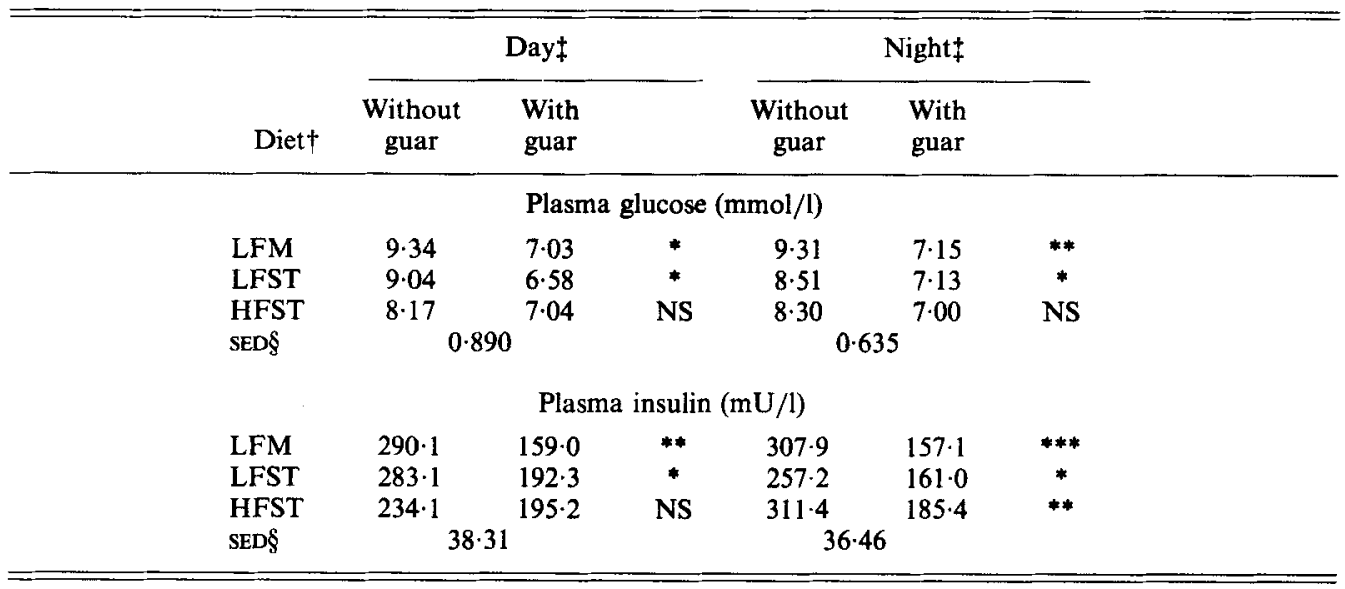

NS, not significant.

* $P<0.05,{ }^{* *} P<0.01, * * * P<0.001$.

There was no significant effect of dietary fat.

$\dagger$ For details of diets, see Table 1.

$\ddagger$ The only significant difference between day and night values was for plasma insulin concentration following diet HFST without guar gum $(P<0.01)$ (glucose, SED 0.449 ; insulin, SED 25.45).

$\S$ SED for comparison of diets using the harmonic mean number of pigs/diet (5.29) based on interactions between pigs and diets $(21 \mathrm{df})$.

The mean times from the beginning of the meal to the peak plasma glucose and insulin concentrations are shown in Table 4 . These times were not significantly affected by the type or amount of dietary fat in the absence of guar gum, but in the presence of guar gum some significant effects of dietary fat on the time taken to reach the glucose peak were seen. The mean time taken to reach both plasma glucose and insulin peaks was increased for all diets by the addition of guar gum, but the differences were not always significant.

Figs. 1 and 2 show the mean post-prandial plasma glucose and insulin profiles over $24 \mathrm{~h}$ for all diets. Dietary fat did not affect either plasma glucose or insulin concentrations in equivalent samples over the $24 \mathrm{~h}$ period, but the addition of guar gum to the diets did result in some significant decreases to both. These were due, at least in part, to the increase in time taken to reach the peak concentrations after feeding.

\section{DISCUSSION}

In general, our results confirm those of Leeds et al. (1980) who used a diet of similar composition to diet LFM to establish that the pig was a suitable model for man in studies on the mode of action of guar gum.

Pre-prandial plasma glucose concentrations remained unaffected by the addition of guar gum to the diet. No effect was expected, since the major action of guar gum is in reducing post-prandial hyperglycaemia as emphasized by Hockaday et al. (1979). Although there was some indication of an effect of guar gum on pre-prandial plasma insulin concentrations, the difference was not statistically significant, perhaps because of the large variation between samples. 
Table 4. Time (min) from beginning of the meal to peak plasma glucose and insulin concentrations after pigs received diets with different types and levels of fat, without and with guar gum

(Mean values and standard error of differences between means)

\begin{tabular}{|c|c|c|c|c|c|c|}
\hline \multirow[b]{2}{*}{ Diet $†$} & \multicolumn{3}{|c|}{ Day $\ddagger$} & \multicolumn{3}{|c|}{ Night $\ddagger$} \\
\hline & $\begin{array}{l}\text { Without } \\
\text { guar }\end{array}$ & $\begin{array}{l}\text { With } \\
\text { guar }\end{array}$ & & $\begin{array}{l}\text { Without } \\
\text { guar }\end{array}$ & $\begin{array}{l}\text { With } \\
\text { guar }\end{array}$ & \\
\hline \multicolumn{7}{|c|}{ Plasma glucose } \\
\hline $\begin{array}{l}\text { LFM } \\
\text { LFST } \\
\text { HFST } \\
\text { SED§ }\end{array}$ & $\begin{array}{l}21 \\
15 \\
15\end{array}$ & $\begin{array}{l}29^{\mathrm{s}, \mathrm{b}} \\
26^{\mathrm{a}} \\
38^{\mathrm{b}}\end{array}$ & $\begin{array}{l}\text { NS } \\
* * \\
* * *\end{array}$ & $\begin{array}{l}26 \\
15 \\
17\end{array}$ & $\begin{array}{l}46^{\mathrm{a}} \\
25^{\mathrm{b}} \\
35^{\mathrm{a}, \mathrm{b}}\end{array}$ & $\begin{array}{l}* \\
\text { NS } \\
\text { NS }\end{array}$ \\
\hline \multicolumn{7}{|c|}{ Plasma insulin } \\
\hline $\begin{array}{l}\text { LFM } \\
\text { LFST } \\
\text { HFST } \\
\text { SED\$ }\end{array}$ & $\begin{array}{l}25 \\
40 \\
25\end{array}$ & $\begin{array}{l}43 \\
55 \\
60\end{array}$ & $\begin{array}{l}\text { NS } \\
\text { NS } \\
* * *\end{array}$ & $\begin{array}{l}29 \\
30 \\
26\end{array}$ & $\begin{array}{l}55 \\
49 \\
60\end{array}$ & $\begin{array}{l}\text { NS } \\
\text { NS } \\
*\end{array}$ \\
\hline
\end{tabular}

NS, not significant.

${ }^{*} P<0.05 ;{ }^{* *} P<0.01 ; * * * P<0.001$.

a. b Values within a vertical column with different superscripts were significantly different $(P<0.05)$.

+ For details of diets, see Table 1.

$\ddagger$ The only significant difference between day and night values was for diet LFM with guar gum $(P<0.05)$ for the glucose peak (glucose, SED 6.5, insulin, SED 9.2).

$\S$ SED for comparison of diets using the harmonic mean number of pigs/diet (5-29) based on interactions between pigs and diets $(21 \mathrm{df})$.

Addition of guar gum to all three diets reduced the mean peak post-prandial plasma glucose concentration but the effect was smaller, and non-significant, for diet HFST than for the other diets. Although dietary fat did not significantly affect the mean peak post-prandial plasma glucose concentration, diet HFST produced a smaller rise than diets LFM and LFST. This might be explained (in part) by the fact that diet HFST contained $19 \%$ less starch than diets LFM and LFST and there was, therefore, less glucose for absorption. In turn there was thus less glucose, or glucose polymer, upon which guar gum could exert an effect, although a clear trend was still seen. The post-prandial plasma glucose concentrations were lower in general than those reported by Leeds et al. (1980), probably because a lower level of feeding was used in the present trial.

Although the effect was not significant with diet HFST during the day, addition of guar gum to all three diets greatly reduced the mean peak post-prandial plasma insulin concentration. This reduction in insulin concentration might have been due to a slower rate of absorption of glucose from the small intestine.

There was a trend for guar gum to delay the appearance of the post-prandial peak in plasma glucose and insulin concentrations. However, these results are difficult to interpret accurately because samples were taken only every 15 min during the first hour after feeding, so the true peak values may not have been detected. This problem would have been reduced by more frequent sampling during this period.

There was only one instance of an apparent effect of dietary fat on either plasma glucose or plasma insulin levels: this was the significantly higher pre-prandial insulin value for diet 

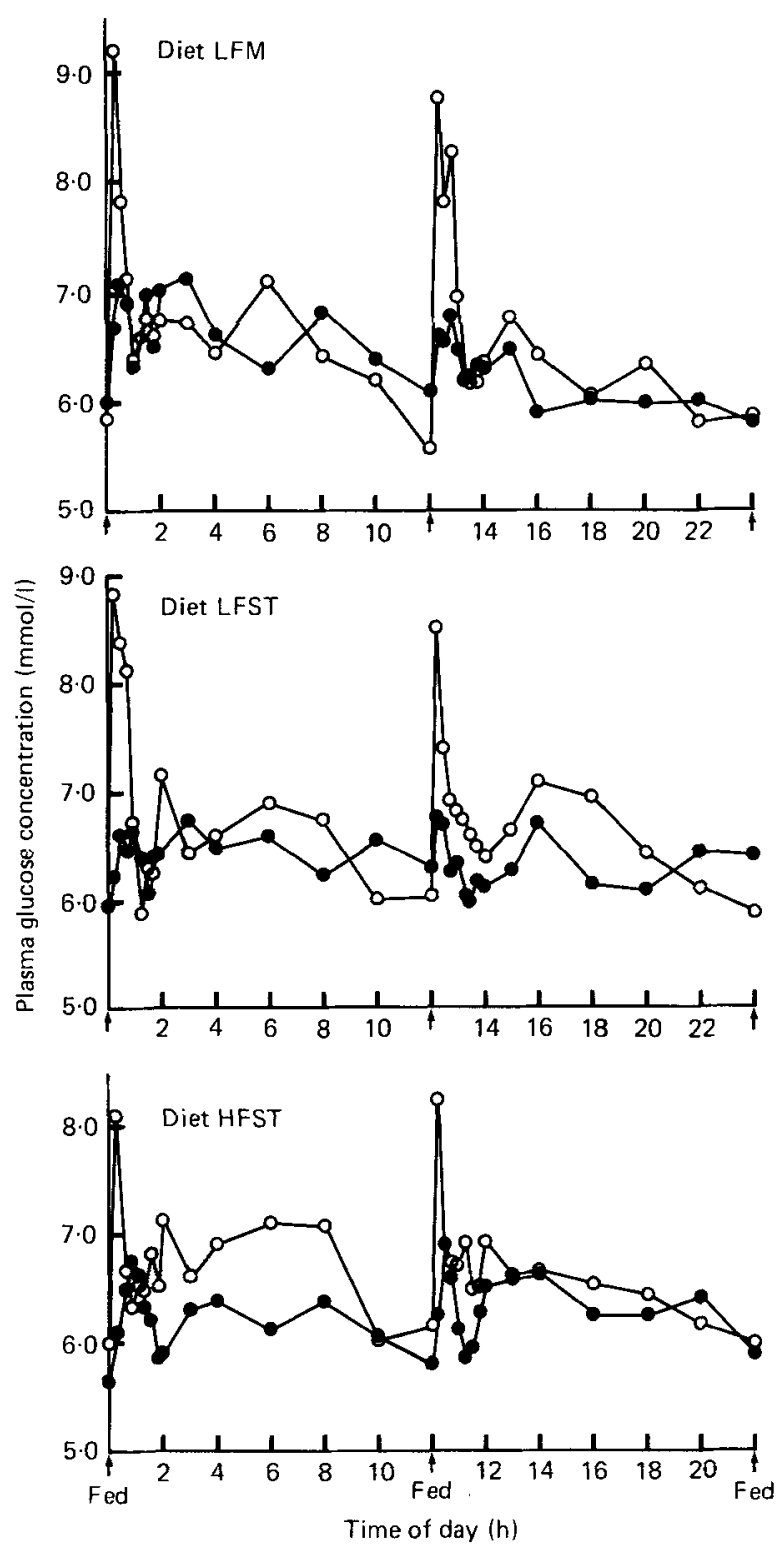

Fig. 1. Plasma glucose concentrations over a $24 \mathrm{~h}$ period after pigs received diets with different types and levels of fat, without $(O)$ or with $(O)$ guar gum (mean values for six pigs). For details of diets, see Table 1 .

HFST before the day feed. Although the night value for this diet was also higher than the other two diets, the difference was not significant. No effect of dietary fat was seen when the diets were fed with guar gum. These results indicate that source and level of dietary fat had little effect on plasma glucose and insulin concentrations. The similar mean peak post-prandial plasma insulin concentrations for all three diets (even though diet HFST contained $19 \%$ less glucose) may be explained by the fact that fat is a potent stimulus to 

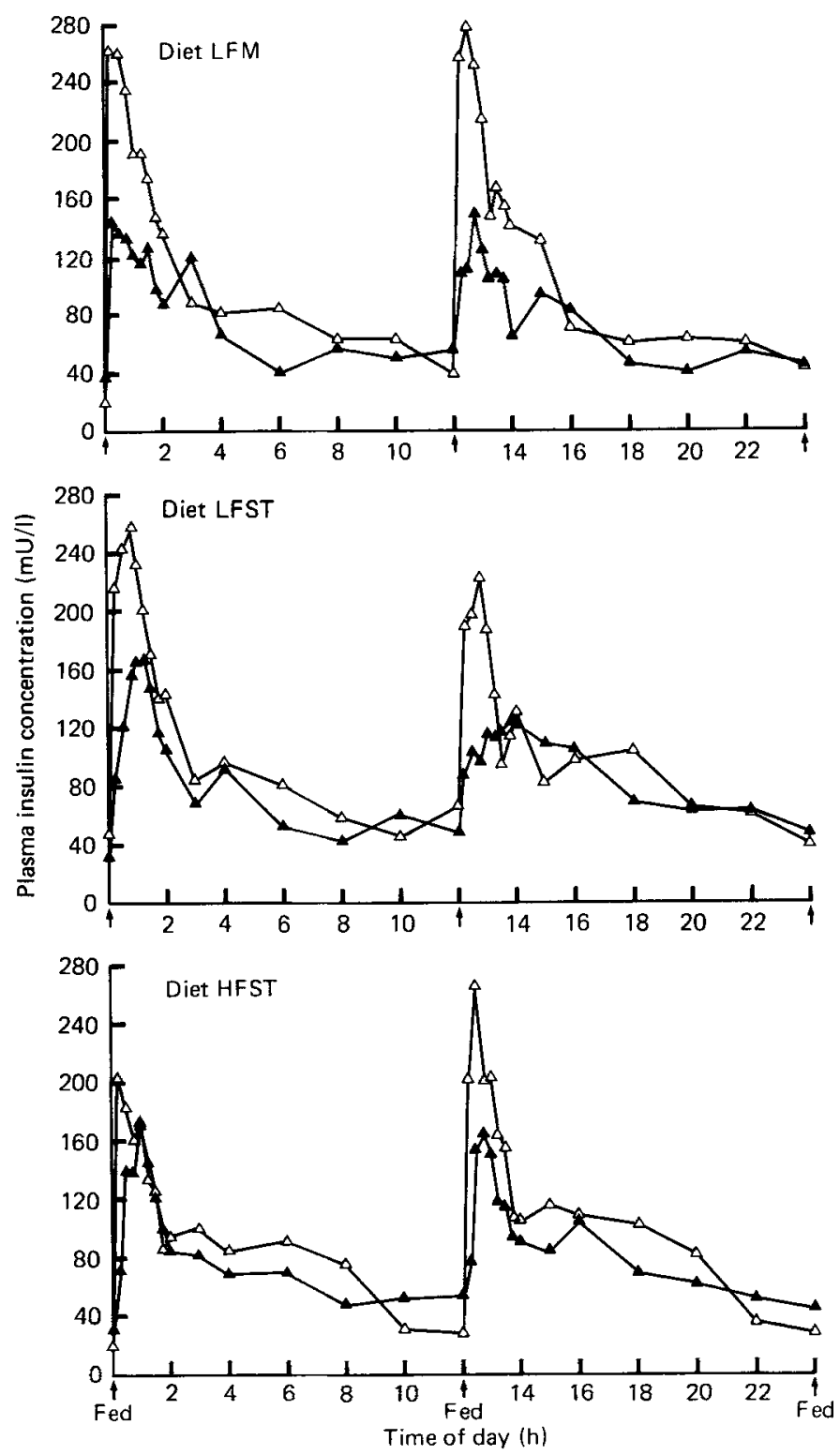

Fig. 2. Plasma insulin concentrations over a $24 \mathrm{~h}$ period after pigs received diets with different types and levels of fat, without $(\Delta)$ or with $(\Delta)$ guar gum (mean values for six pigs). For details of diets, see Table 1.

gastric inhibitory polypeptide (GIP) release and GIP has been shown to potentiate glucose-induced insulin secretion (Dupré et al. 1973). In a recent study in man, Collier \& O'Dea (1983) found that co-ingestion of fat ( $50 \mathrm{~g}$ butter) with a carbohydrate meal $(284 \mathrm{~g}$ boiled potato giving $50 \mathrm{~g}$ carbohydrate) reduced the post-prandial glucose response to the carbohydrate intake, but had no effect on the insulin response. The latter result was probably due to the observed raised post-prandial plasma GIP levels. There appear to be 
no other studies on the influence of source or level of fat intake on blood glucose and insulin levels.

As a high fat concentration in the dry matter might be expected to reduce the rate of emptying of digesta from the stomach, it was thought that diet HFST might have delayed the arrival of the peak post-prandial plasma concentration. However, in the present study, a change in the level and source of dietary fat did not appear to have any effect in this respect, except with diets containing guar gum. The reason for this latter result is not clear although, as already mentioned, because samples were taken only every 15 min during the first hour after feeding, the responses observed cannot be interpreted with great accuracy.

Since the addition of guar gum to diet HFST produced a smaller reduction in post-prandial plasma glucose response than when it was added to diets LFM or LFST, it might be argued that it is preferable to use a low-fat diet, e.g. LFM or LFST, to achieve maximal responses when examining the mode of action of guar gum. Nevertheless, diet HFST is more typical, in its gross chemical composition, of that eaten by man and, since the pig is being used as a model for man, it would seem preferable to use such a diet.

If a high-fat diet is to be used in studies such as this, it seems likely that a larger number of animals would be required to demonstrate a greater number of statistically-significant effects of guar gum than seen here. The lower level of starch in the high-fat diet probably contributed to the reduced plasma glucose levels. In addition, the possibility that the extra fat exerted a direct effect, by slowing gastric emptying or delaying the processes of digestion and absorption, merits further study.

The authors thank Mr H. A. Smith for his skilled technical assistance and Mr A. D. Simmonds for advice with the plasma insulin measurements. They are also grateful to $\mathrm{Mr}$ A. R. Jones and his staff for the care of the animals, Dr A. G. Low for much useful discussion and Mrs Rosemary J. Fulford for statistical advice. They thank R. M. W. Hopkins of the Meyhall Chemical Company for the gift of guar gum. A.L.R. gratefully acknowledges receipt of an Agricultural Research Council Research Studentship.

\section{REFERENCES}

Barber, R. S., Braude, R., Mitchell, K. G. \& Pittman, R. J. (1972). Animal Production 14, 199-208.

Collier, G. \& O'Dea, K. (1983). American Journal of Clinical Nutrition 37, 941-944.

Dupré, J., Ross, S. A., Watson, D. \& Brown, J. C. (1973). Journal of Clinical Endocrinology and Metabolism 37, $826-828$.

Hockaday, T. D. R., Jenkins, D. J. A., Wolever, T. M. S., Nineham, R., Taylor, R. \& Bacon, S. (1979). British Medical Journal i, 1353.

Jenkins, D. J. A., Leeds, A. R., Gassull, M. A., Wolever, T. M. S., Goff, D. V., Alberti, K. G. M. M. \& Hockaday, T. D. R. (1976). Lancet ii, 172-174.

Jenkins, D. J. A., Wolever, T. M. S., Taylor, R. H., Reynolds, D., Nineham, R. \& Hockaday, T. D. R. (1980). British Medical Journal 280, 1353-1354.

Leeds, A. R., Kang, S. S., Low, A. G. \& Sambrook, I. E. (1980). Proceedings of the Nutrition Society 39, 44 A.

Tindal, J. S., Knaggs, G. S., Hart, I. C. \& Blake, L. A. (1978). Journal of Endocrinology 76, 333-346. 